\title{
A Comparative Study of Stress level of Male and Female Nurses in ICU
}

\author{
Article by Jolly Sabu \\ Clinical Research, Texila American University, India \\ E-mail: jollymoolakkatt@yahoo.com
}

\begin{abstract}
The purpose of this study is to assess the perceived stress in male and female nurses working in ICU. According to the World Health Organization, stress is a significant problem of our times and affects both physical as well as the mental health of people. ... Stress coping methods are the cognitive, behavioral and psychological efforts to deal with stress.
\end{abstract}

\section{Introduction}

Stress has always been part of human life. Stress is a physical or emotional state of response present in a person as a result of dynamism in life. It is intensified in a nonspecific response to an internal or external environmental change or threat.

Stress is a condition wherein any factors interact with the individual to change (disrupt/enhance) her/his psychological or physiological conditions so that the persons mind and body are forced to deviate from its normal way of functioning. Stress in human life is often experienced with tension, anxiety, worry, and pressure. It is an accepted fact that stress is useful in life but it can have either beneficial or detrimental effects. They can be physical, social, emotional, intellectual, and spiritual. World Health Organization is of the opinion that work place stress is estimated to cost companies more than 300 million dollars a year due to poor performance, absenteeism and health costs.

Professional stress or job stress poses a threat to physical health. Work related stress in the life of organized workers, consequently, affects the health of organizations. Numerous studies have indicated that job stress is significant in nursing. It was found that job stress brought about hazardous impacts not only on nurses' health but also their abilities to cope with job demands. This will seriously impair the provision of quality care and the efficacy of health services delivery. In particular, the job stress of nurses working in acute and specialized care units has been widely studied. Heavy work load, poor staffing, dealing with death and dying, inter-staff conflict, strain of shift work, careers and lack of resources and organizational support has been identified as the major source of job stress. It has also been found that nurses experience job stress differently. Some studies found that stress level was significantly higher in junior nurses than in the senior nurses.

1. The purpose of this research is to assess the professional stress level of male and female staff nurse working in ICU's

2. To compare the professional stress level among both the male and female staff nurses in ICU's.

3. To co-relate the findings with demographic variables.

4. Early identification of stress in staff nurses.

5. To inform the nursing administrators to implement the strategies to reduce stress in the nursing staff.

\section{Limitations}

a) The study will be limited to 60 staff nurses working in different ICUs of Hospitals in Al Ain City.

b) Those who are willing to participate in the study and those who are present during the period of data collection.

c) The extraneous variables like age, sex, income, type of family were beyond the investigator's control.

d) The study was limited to the experience level of the researcher. 
DOI: $10.21522 / \mathrm{TIJCR} .2014 .04 .02 . A r t 005$

ISSN: $2520-3096$

\section{Method}

The conceptual framework adapted for the study was based on Lazarus's Transactional model of stress. The focus of this model, the first stage in his model is primary appraisal where the subject analyzes the stressor and determines if it will be positive or negative, exciting or harmful, etc. The second stage is secondary appraisal, where the subject determines if he or she can cope with the given stressor. Even if the stressor is determined as harmful in the first stage, if the subject decides he or she can cope with it in the second stage, stress will be kept at a minimum.

The steps undertaken for gathering and organizing the data collected were; research approach, research design, study setting, population under study, sample and sampling techniques, criteria for selection of samples, development and description of tools, pilot study, data collection and plan for data analysis.

\section{Research approach}

A research approach tells the researcher what data to collect and how to analyze it. It also suggests possible conclusion to be drawn from the data.

According to Polit and Hungler "Research is systematic inquiry that uses disciplined methods to answer questions or solve problems. The ultimate goal of research is to develop, refine, and expand a body of knowledge."

It is a fact finding investigation with adequate interpretation. It is designed to gather descriptive information and provides information for formulating more sophisticated study: Data collection by using one or more appropriate methods; observation, interviewing and mail questionnaire.

In view of the nature of the problem under study and to accomplish objectives of the study descriptive survey approach which is exploratory in nature was considered appropriate to describe professional stress among male and female staff nurses working in ICU in selected Hospitals of AlAin city.

\section{Company profile}

Al Noor hospital: is one of the leading private hospitals in Al Ain where all the patients are accommodating in accordance to the mantra "You are in safe hands. Hospital is accredited by JCI, maintained 3 consecutive times and ISO certification will attest to its quality services. Bed capacity of 52 beds with 7 in ICU, 4 Operation Theatres and other critical services are readily available here.

NMC Hospital: is a multispecialty hospital provides quality and trusted healthcare services to the people of Al Ain and the surrounding area. The hospital is affiliated with all major national as well as international insurance companies and engages direct billing with insurance companies and third party administrators. 82 patient beds, 7 ICU beds and 5 operation beds are available here.

Oasis Hospital: has been serving the residents of the eastern region since beyond 1960.It is the first private hospital accredited in the emirate of Abu Dhabi for JCI with a vision to be the hospital of choice in Al Ain and the neighboring community. It has 109 beds with 7 ICU beds, 4 Operation theatres and other critical services.

\section{Problem statement}

A comparative study has been assess the professional stress level of male and female staff nurses working in ICU of selected hospitals in Al Ain city.

Nursing work situation has certain demands. Meeting demands can lead to psychological distress. Stress at work is a real problem both to the organization and its workers. Stress can be physical and psychological and often leads to decreased quality of life and poor organizational performance. Stressors at work can cause stress and individuals exposed to these stressors will experience stress in their personal life and which will ultimately affect their performance at work. Stress at work refers to occupational phenomenon associated with specific situations, characteristics of the work cause environment including individual perceptions and reactions in the context of the workplace.

Nursing provides a wide range of potential workplace stress. Nursing is a work environment that is notable for high work stress and high demands. Stress is also associated with high levels of emotional, cognitive, and physical strain. Nursing is a typically stressful and emotionally demanding work. As such the burden of care giving has generally produced stress and distress among healthcare professionals. Nurses engage in physically demanding tasks on a daily basis and are often for occupational burnout and 
physical complaints merely due to high demands at work. This consequently results in increased dissatisfaction with their career. The current study concerns with management of workplace stress in critical care setting. The studies associated high turnover among healthcare professionals with high levels of work strain and stress and low levels of work satisfaction.

There are various factors that can influence the stress in the critical nursing staff. Some of the factors include

(A) Lack of confidence and competence in critical care area.

(B) New technologies, change in leadership work environment

(C) Lack of capacity to care for self. With new roles and new expectations,

(D) Limited training in the new work tasks,

(E) increased consumption of healthcare goods and services,

(F) short-age of nursing staff and insufficient competence at work task

As can be seen, an increased level of stress can lead to high staff turnover, low quality of care and organizational inefficiency the present study could be considered important for understanding stress management and can be managed by some of the following strategies.

- Nursing professionals working in the hospital settings will be able to find opportunities to teach and improve the knowledge of nurses regarding stress and its better management.

- Mastery of working environmental demands and sufficient resources and improved communication will be helpful to resolve the stress and improve coping abilities among nurses.

- Sound knowledge and clinical assessment skills among nurses will be important factors in reducing stress and improving coping abilities.

- Implications for practice include fostering planned discussion, sessions and continued education to improve counseling skills related to bereavement among nurses will be necessary for preventing stress and promoting coping abilities.

- Nursing professionals working in the hospital settings will be able to find opportunities to teach and improve the knowledge of nurses regarding stress and its better management.

- Mastery of working environmental demands and sufficient resources and improved communication will be helpful to resolve the stress and improve coping abilities among nurses.

- Sound knowledge and clinical assessment skills among nurses will be important factors in reducing stress and improving coping abilities.

- Implications for practice include fostering planned discussion, sessions and continued education to improve counseling skills related to bereavement among nurses will be necessary for preventing stress and promoting coping abilities.

- Research approach : Quantitative approach

- Research design: Comparative descriptive design

- Setting: 3 Hospitals in AL AIN City

- Sampling technique: Convenient sampling technique

- Sample size: 60 (30 male and 30 female)

- Population: ICU staff nurse

- Study duration: 90 days.

\section{Result}

Section-I deals with percentage distribution of samples. This shows that equal number of male (50\%) and female (50\%) staff nurses are participated in the study, the $66.7 \%$ of the male and $76.7 \%$ of female samples are in the age group of $21-25$ years and remaining $33.3 \%$ and $23.3 \%$ are in the age group of 2630years.no samples have age more than 30 years.

Majorities of the male and female staff nurses, $66.7 \%$ are completed general nursing and $33.3 \%$ are completed BSC nursing. 50\% of the male staff nurses and $56.8 \%$ of female staff nurses have experience in between 0-2years. $26.7 \%$ males and $30 \%$ of females are in the 2-4 year experience group and $23.3 \%$ of males have experience in between 4-6years.

No one has experience more than 6 years 
DOI: $10.21522 / \mathrm{TIJCR} .2014 .04 .02 . A r t 005$

ISSN: $2520-3096$

Section-I: Description of demographic data

Table 1. Frequency distribution of staff nurses as per demographic variables

\begin{tabular}{|l|l|l|l|l|}
\hline \multirow{2}{*}{ Demographical data } & \multicolumn{2}{|l|}{ Males } & \multicolumn{2}{l|}{ Females } \\
\cline { 2 - 5 } & Frequency & Percentage & Frequency & Percentage \\
\hline Age & & & & \\
\hline $21-25$ yrs & 20 & 66.7 & 23 & 76.7 \\
\hline 26-30yrs & 10 & 33.3 & 7 & 23.3 \\
\hline 30-35yrs & 0 & 0 & 0 & 0 \\
\hline 36 and above & 0 & 0 & 0 & 0 \\
\hline Gender & 30 & 50.0 & 30 & 50.0 \\
\hline $\begin{array}{l}\text { Educational } \\
\text { qualification }\end{array}$ & & & & \\
\hline BSC Nursing & 10 & 33.4 & 10 & 33.4 \\
\hline $\begin{array}{l}\text { GNM } \\
\text { ICU Experience } 0-2\end{array}$ & 20 & 66.6 & 20 & 66.6 \\
\hline yrs & & & & \\
\hline 2- 4 yrs & 15 & 50.0 & 17 & 56.8 \\
\hline 4-6 yrs & 8 & 26.7 & 9 & 30.0 \\
\hline$>$ 6 yrs & 7 & 23.3 & 2 & 6.6 \\
\hline
\end{tabular}

$\mathrm{N}=60$

Data presented in table 1 shows that majority of staff nurses were from age group between 21-

25 years, i.e. 20(66.7\%) are males and 23(76.7\%) are females. Staff nurses having BSC (N) and

GNM degree were equal in both sex i.e. 10(33.4\%) BSC (N) and 20(66.6\%) GNM. Among the male nurses $15(50 \%)$ are from non-experienced group and 15(50\%) are from experienced group. Whereas among females only 17(56.8\%) are from non-experienced and 13(43.2\%) are from experienced group.

\section{Section-II: Findings related to professional stress among staff nurse}

Table 2. Frequency distribution of male and female staff nurses as per professional stress level in ICU.

\begin{tabular}{|c|c|c|c|c|}
\hline \multirow{3}{*}{ Professional stress level } & \multicolumn{4}{|l|}{ Gender } \\
\hline & \multicolumn{2}{|l|}{ Male } & \multicolumn{2}{|l|}{ Female } \\
\hline & $\begin{array}{l}\text { Frequenc } \\
\text { y }\end{array}$ & Percentage & Frequency & Percentage \\
\hline No stress & 13 & $43.3 \%$ & 8 & $26.7 \%$ \\
\hline Mild stress & 15 & $50 \%$ & 19 & $63.3 \%$ \\
\hline Moderate stress & 2 & $6.7 \%$ & 3 & $10 \%$ \\
\hline Total & 30 & 100 & 30 & 100 \\
\hline
\end{tabular}

$\mathrm{N}=60$

Table 2 describes that among total population of 60 staff nurses mild stress group consisted of $19(63.3 \%)$ females compared to only $15(50 \%)$ male staff nurses, whereas no stress was observed among $13(43.3 \%)$ male and $8(26.7 \%)$ female staff nurses. 

Volume 4, Issue 2, Nov 2017

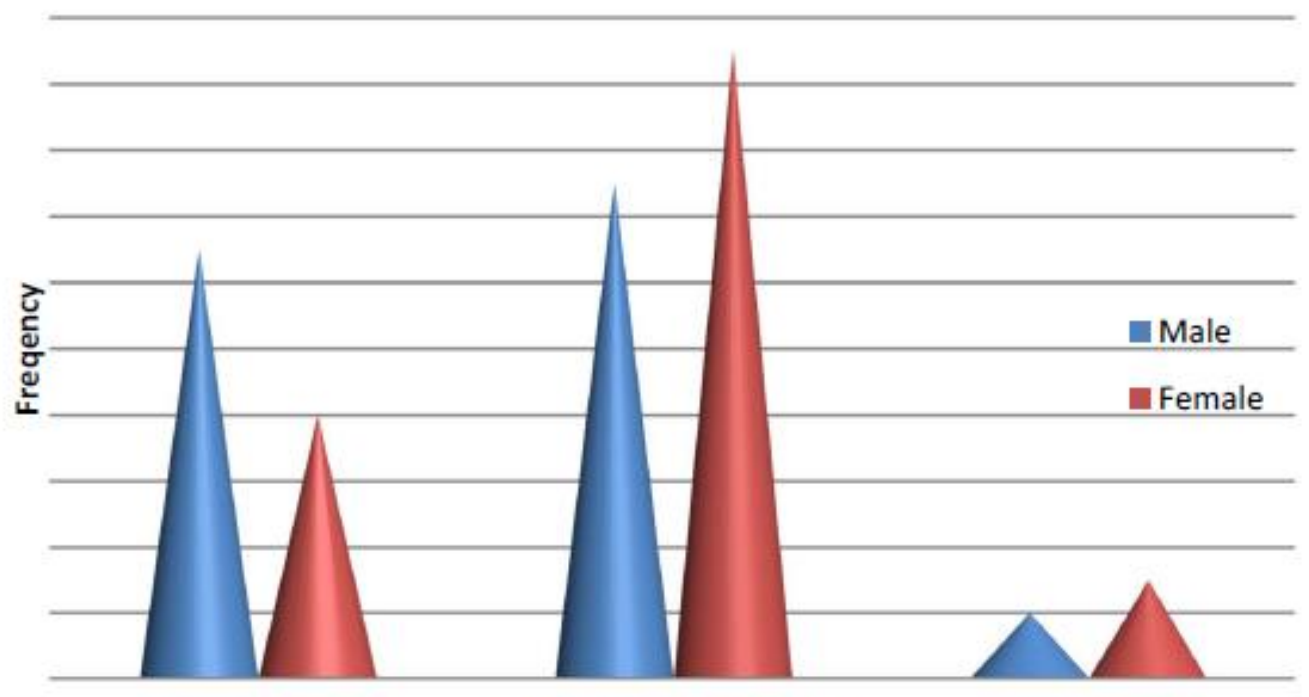

Professional stress level

Figure 1. Frequency distribution of male and female staff nurses as per professional stress level

Data represented in the above cone diagram describes that most of the staff nurses in both group have mild stress, and no stress has been observed among majority of the male staff nurses.

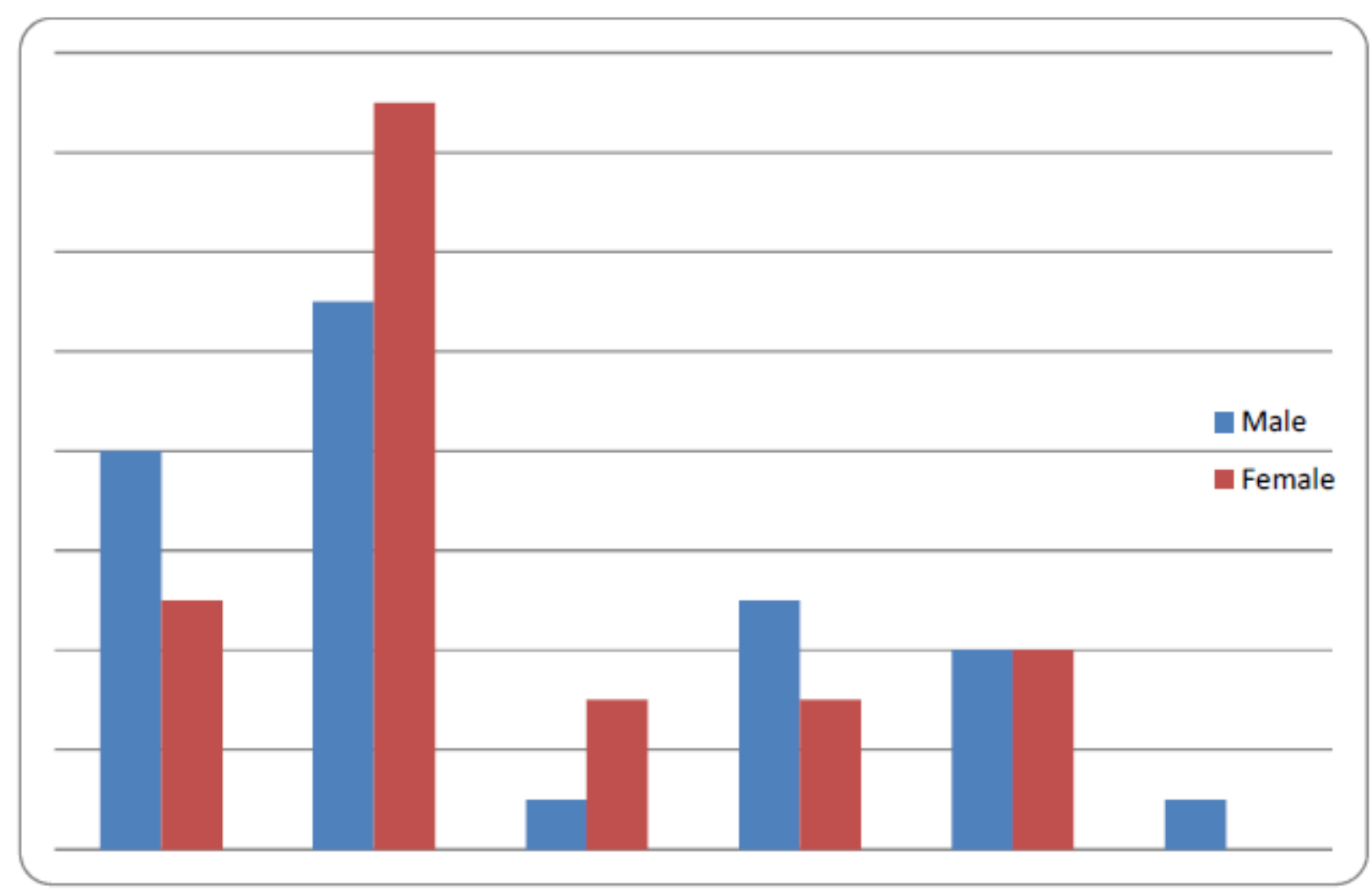

Figure 2. Bar diagram showing the age wise distribution of professional stress level among male and female staff nurses 
DOI: $10.21522 / \mathrm{TIJCR} .2014 .04 .02 . A r t 005$

ISSN: 2520-3096

Number of female staff nurses in the mild stress group is higher than the number of male staff nurses whereas in no stress group number of male staff nurses are higher than female staff nurses among the age group of 21-25 years. In 26-30 years of age group the numbers of males are higher than females in no stress group and same in mild stress group.

\section{Discussion}

Professional stress is the result of interaction between characteristics of individual persons, resources and stress factors which are physical, mental or social, related to the work environment. Professional stress among nurses is associated with a variety of personal and institutional factors. Working in areas such as the emergency room or the intense care unit, patients require a greater level of care. These situations can require immediate response by the nursing staff and can often cause high stress levels. The present study was assessing professional stress among male and female staff nurses working in ICUs of selected hospitals in Al Ain city. The level of stress has been classified in this study as no stress, mild stress, moderate stress and severe stress. The findings of this study have been discussed with reference to the objectives and hypothesis.

In this study we have equal number of male and female staff nurses are there. The most of the male and female samples $72 \%$ are in the age group of $21-25$ years. $66.6 \%$ of the samples are completed general nursing and more than $50 \%$ of the samples have experience less than 2 years.

Descriptive research approach was used to assess the stress level of staff nurses from Oasis hospital, Al Noor hospital, NMC hospital. The sample size was 60, 30 male and 30 female staff nurses taken by nonprobability convenience sampling technique. Both male and female BSC and GNM nurses were included in the study and ANM staff nurses were excluded from the study. David Fontana's professional life stress scale was modified to assess the stress level of male and female staff nurses working in ICU. In the questionnaire there are 2 sections $1^{\text {st }}$ section deals with the demographical data and the $2^{\text {nd }}$ section contains 18 objective type questions to assess the stress level of the staff nurses. 15 to 20 minutes were taken to fill the questionnaire. According to score the samples are classified into no stress, mild stress, and moderate stress. There 21 samples have no stress and 34 have mild stress and 5 have moderate stress, nobody has severe stress in the sample. The average score obtained by the male staff nurses and female staff nurses were 11.6 and 12.7 respectively.

The study conducted in managing stress in nursing professionals in this study majority of nurses (59/90-65\%) perceived stress, supported that stress in ICU is high compare to other areas. Stress was found to be significantly more in wards and ICU rather than operation theater $(\mathrm{p}<0.05)$ stress was found to be less in staff nurses having less than $50 \%$ of mark in $12^{\text {th }}$ standard as computed too others. Work stress was greater perceived cause of stress in nurses conflict between work and home was major factor.

In this study two sample t test were used to compare the stress level of male and female staff nurses. The values found by ' $t$ ' test is -0.74 and ' $p$ ' value 0.232 shows that there is no significant change in the professional stress of male and female staff nurses. Detail description of the data were shown in the section III

Co-relation between the Professional stress and demographical variables are done by Chi square test. ' $p$ ' values of all the demographical variables were found to be greater than 0.05 that indicate that there is no association between demographical variables and professional stress.

The study conducted on Job stress and intention to quit in newly-graduated nurses during the first three months of work in Taiwan supporting the finding shown above in this study. To identify job stress and intention to quit in newly-graduated nurses during the first three months of their work at two different levels of hospitals and to understand factors that may influence their retention. Subjects experienced somewhat stressful conditions (Mean $=2.89$, SD 0.62) and 31.5\% intended to quit. Job stress was the highest at 0-1 month and the intention to quit was highest at 1-2 months. The intention-to-quit group had significantly higher job stress with regard to roles/interpersonal relationships than the intention-to-stay group [ $\mathrm{t}(144)=2.65, \mathrm{p}=0.009]$. Logistic regressions indicated that higher job stress (odds ratio $=2.26$; 95\% CI 1.14-4.51), working at a medical centre (odds ratio $=3.61 ; 95 \%$ CI $1.10-10.92$ ) and not having had a clinical practicum in the working hospital (odds ratio $=2.41 ; 95 \%$ CI 1.01-5.77) were significant predictors associated with the intention to quit. 


\section{Conclusion}

\section{The conclusion drawn from the findings of the study are as follows:}

The two sample t test was used to compare the professional stress levels of male and female staff nurses working in ICUs and found that there is no significant change in the stress level of male and female staff nurses. The associations were checked with demographical variables by using chi-square test and found that demographical variables have no association with professional stress.

Early identification of stress in staff nurses will help in increase the work performance and good patient care without any physical and mental problems. This will give an idea to top order for plan educational and stress management programs to reduce the stress levels in staff nurses and increase quality of patient care and productivity. Professional stress is the result of interaction between characteristics of individual persons, resources and stress factors which are physical, mental or social, related to the work environment. Professional stress among nurses is associated with a variety of personal and institutional factors. Working in areas such as the emergency room or the intense care unit, patients require a greater level of care. These situations can require immediate response by the nursing staff and can often cause high stress levels. The present study was assessing professional stress among male and female staff nurses working in ICUs of selected hospitals in Al Ain city. The level of stress has been classified in this study as no stress, mild stress, moderate stress and severe stress. The findings of this study have been discussed with reference to the objectives and hypothesis

The findings of the study can be used in the following areas:

- Nursing practice

- Nursing education

- Nursing administration

- Nursing Research

\section{Acknowledgement}

I sincerely thank the Almighty God for his glorious blessing infinite mercy, abundant love and spiritual guidance all the way through my life.

I would like to thank the Management of the organizations for allowing me to study their organizational structure and on the activities who shared their valuable time even during their office timings, and gave me full support and beneficial information's and tips to study and complete the project.

A Special gratitude I give to my colleagues whose contribution in stimulating suggestions and encouragements.

\section{References}

[1]. Adall E, Priamim. Burnout among nurses in ICUs, medical wards and emergency departments in Greek Hospitals. Nursing Journal. 2002 July-Sep; 5(6): 1-19.

[2]. Alnems A, Aboads F, Yousef MAL, Abotabar N. nuurses perceived job related stress and job satisfaction.2005 Jun. URL: www.paper4.u.

[3]. Burgess L, Irvine F, Wallymahmed A. personality stress and coping in intensive care nurses. Nursing in critical care.2010 Mar-Jun 15(3):129-40.

[4]. Bruziene R. The stress experience of nursing staff in intensive care therapy.URL: www.pubmed.com.

[5]. Bowman GD, Stern M. Adjustment to occupational stress: the relationship of perceived control of effectiveness of coping strategies. Journal of Counseling Psychology 1995; 24(3): 294-303.

[6]. Best W, John, James V, Kohn. Research in education. 7th edition. New Delhi: Prentice Hall of India; 2000. p. 76-81.

[7]. Corr M. Reducing occupational stress on intensive care, nursing in critical care. British Journal of Nursing 2000; 5: 76-81.

[8]. Cozens JF, Payne RL. Stress in health professionals. Journal of adolescent medicine health.2000 Jan; 12.

[9]. Chang EM, Daly JW, Hancock KM, Bidewell J, Johnson A, Lambert VA, Lambert CE. The relationship among work place stressors, coping methods, demographic characteristics, and health in Australian nurses. Journal of professional nursing. 2006 Jan 22(1):30-38. 
DOI: 10.21522/TIJCR.2014.04.02.Art005

ISSN: $2520-3096$

[10]. DCua jk. Psychological distress and quality of life among medical student of Assam medical college. Indian journal of psychiatry. $2008 \mathrm{Jan}$; 50(2):12-15.

[11]. Delvaux N, Razavi D, Farvacques C. Cancer care - a stress for health professionals. July 2002.URL: www.sciencedirect.com.

[12]. European foundation for the improvement of living and working conditions. Work related stress. www.eurofound.europa.eu.

[13]. Fang LCCY. Nurse's stress factors in the hospital units. Journals of Nursing Administration. 1979 Feb; 9(2): 21-6.

[14]. Gomes R, Curz JF, Cabanelas S. occupational stress in health professionals. URL: www.pubmed.com.

[15]. Hillhouse JJ, Alder CM. Investigating stress effect patterns in hospital staff nurses. Social science and medicine. 1997 Dec 45(12): 1781- 1788.

[16]. Hall DS. Work related stress of registered nurses in a hospital setting. J Nurses Staff Dev. 2004 Jan-Feb; 20(1): $15-6$.

[17]. Hay D, Oken D. The Psychological Stresses of Intensive Care Unit Nursing. Psychosomatic Medicine, 1972 Mar 34 (2):109-18.

[18]. Heapes N. Teacher stress and burnout in relation to extra-curricular involvement. Teacher Stress and Burnout. 2008Dec: 1-37.

[19]. Kawano Y. Association of job-related stress factors with psychological and somatic symptoms among Japanese hospital nurses. Journal of occupational health .2008 May 50:79-85.

[20]. Lim J, Bogossian F, Ahern K. stress and coping in Australian nurses. Mar 10. 57(1)22-31. URL: www.pubmed.com.

[21]. Lin Yh, Chen CY, Lu SY. Physical discomfort and psychological job stress among male and female telecommunications. 2008 Mar.URL: www.pubmed.com.

[22]. Light I. Tips on stress management for nurses. Health action 2010 Jan 22; 1:10-15.

[23]. Townsend MC. Psychiatric mental health nursing. 4thed. New Delhi: Jaypee brothers' medical publishers; 2007.p.6.

[24]. Mathew AP. Job perception among nurses: the ICU scenario. The nursing journal of India.vol.39.may 1998 May.39.

[25]. Mims A, Stanford T. Stress and burnout among critical care nurses. Journal of emergency nursing. 16(2), 9095.

[26]. Nagaraj CV. Stress a sociopsychological concern. Health action 2010 Jan 22; 1:4-6.

[27]. Philadelphia. Stress signals differ in female and male brains. TS-Si News Service 2010 June 17.

[28]. Supe A. Managing stress in nursing professionals. The nursing journal of India .oct 2000Oct 41(9):12-14.

[29]. Sist. Florry. Student nurses problems and guidance. The nursing journal of India.1997 Jul 38(7).

[30]. Shoter M, Stayt LC. Critical care nurses experiences of grief in an adult intensive care unit. Journal of advance nursing. 2010 Jan; 66 (1):159-67.

[31]. Valentine RJ, Bangasser DA. Psychological distress and quality of life among medical student of Assam medical college. Indian journal of psychiatry. 2008 Jan, 50.

[32]. Vicar AMC. Integrative literature reviews and meta-analyses. Journal of Advanced Nursing 2002 Jun; 44:6, 633-642.

[33]. Wheeler HH, Riding R. Occupational stress on general nurses and midwives. British Journal of Nursing 1994; 3: 527-34.

[34]. Wu H, Chi TS, Wang L, Jin YP. Occupational stress among hospital nurses. Journal of advance nursing. 2010 Mar 66(3):627- 34.

[35]. Yeh MC, Yu S. Job stress and intention to quit in newly graduated nurses during the first three months of work. Journal of clinical nursing, Dec 2009. 18(24):3450-60.

[36]. Zhu YLB. Numerical analysis and comparison on stress between male and female academic faculty in Chinese universities. Second international conference information and computing science 2009 May 21-22; Manchester 2009.p. 390-3. 